\title{
A Critical Analysis of Social Justice as the Basis of Policy Making in the Light of Arguments by Amartya Sen
}

\author{
Joydeep Sil \\ PhD Scholar, National Institute of Educational Planning and Administration (NIEPA), New Delhi, India
}

\begin{abstract}
In his book 'The Idea of Justice', Amartya Sen has critically examined the established theories of 'justice' and forwards his own views about the concept of social justice. As per Sen, injustices in the society need to be evaluated by way of reasoning and reasoned justifications (plural grounding). Only based on such reasoned diagnosis of what causes social injustice, policy measures can be adopted to reduce injustice and advancing justice. Sen has strongly argued against transcendental institutionalism line of reasoning (Locke, Rousseau, Kant, Rawls) as there cannot be one perfectly just social arrangement. He, therefore, discards transcendental proposition of a set of right institutions which would, by default, bring social justice. As per him it is neither necessary nor sufficient for a workable theory of justice. He rather preferred realisation-focussed comparisons of justice (Adam Smith, Marx, J. S. Mill, Condorcet) as it is based on social realisations resulting from actual institutions, actual behaviour and other influences. The focus of the later approach is primarily in the removal of manifest injustice from the society rather than identification of ideal social arrangements and choice of ideal institutions. Sen has drawn analogy for an argument-based public reasoning on rankings of alternatives that can be realised. This is central to the analytical discipline of 'social choice theory' conceptualised by Condorcet and further developed by Kenneth Arrow in the middle of the twentieth century. Sen has constructed his own argument further on the social choice theory by way of focussing on an accomplishment-based understanding of justice which is based on freedom and capabilities of individuals. This paper would attempt to bring out the rationale behind arguments put forward by Sen and its implications in the context of Indian public policy making, in general.
\end{abstract}

Keywords: social justice, social choice, public reasoning, public policy, freedom, capability

DOI: $10.7176 / \mathrm{PPAR} / 10-5-05$

Publication date:May $31^{\text {st }} 2020$

\section{Introduction}

In the introduction chapter of his book 'The Idea of Justice', Amartya Sen has critically examined the established theories of 'justice' and forwards his own views about the concept of social justice. As per Sen, injustices in the society need to be evaluated by way of reasoning and reasoned justifications (plural grounding). Only based on such reasoned diagnosis of what causes social injustice, policy measures can be adopted to reduce injustice and advancing justice. Sen has strongly argued against transcendental institutionalism line of reasoning (Locke, Rousseau, Kant, Rawls) as there cannot be one perfectly just social arrangement. He, therefore, discards transcendental proposition of a set of right institutions which would, by default, bring social justice. As per him it is neither necessary nor sufficient for a workable theory of justice. He rather preferred realisation-focussed comparisonsof justice (Adam Smith, Marx, J. S. Mill, Condorcet) as it is based on social realisations resulting from actual institutions, actual behaviour and other influences. The focus of the later approach is primarily in the removal of manifest injustice from the society rather than identification of ideal social arrangements and choice of ideal institutions.

With references from history and other illustrations, Sen has drawn analogy for an argument-based public reasoning on rankings of alternatives that can be realised. This is central to the analytical discipline of 'social choice theory' conceptualised by Condorcet and further developed by Kenneth Arrow in the middle of the twentieth century. Arguing in favour of reason, Amartya Sen has exemplified the pursuit of reason for probing in to the question of ethical objectivity in terms of reasoned scrutiny. Reasoned scrutiny from different perspectives is an essential aspect of the demands for objectivity for ethical and political convictions.

\section{Freedom and capability}

Sen has constructed his own argument further on the social choice theory by way of focussing on an accomplishment-based understanding of justice which is based on freedom and capabilities of individuals. According to him, social realisation in terms of capabilities empowers people as well as creates deontological demand. Sen points out that means to live is more important to our lives than the kind of life we live. The importance of freedom and opportunities to choose is thus one of the valued aspects of living. More freedom gives us more opportunities to pursue our objectives of life. This aspect of freedom is concerned with capability. The other aspect of freedom is linked to the process of choice itself. This also helps augmenting concerns and commitments towards social life. This is where he departs from the utilitarian approach and develops his capability-based approach with emphasis being laid on 'niti' and 'nyaya'. Whereas niti is organisational propriety 
and behavioural concern; nyaya is the comprehensive concept of realised justice. Sen has argued that niti is to be assessed in terms of nyaya for proper realisation of justice.

In order to provide further insight on the dichotomy between niti and nyaya, Sen has deftly cited instances from The Bhagavadgita - specifically, the intriguing dialogand dilemma between Krishna and Arjuna at the onset of the Kurukshetra war. While Arjuna, the consequentialist, is deeply concerned with the fatal outcome of the war; Krishna, the deontologist, is urging him not to bother about the consequences and perform the role of a warrior consideringhis duty. Here, Sen reflects onsocial implications in terms of distinction and contrast between deontological and consequential approaches to justice. He has strongly argued in favour of the 'comprehensive outcome', which includes the processes involved, rather than only the 'culmination outcome', which exclusively focuses on the final consequence, as a means of accomplishing social justice.

\section{Features of Sen's capability approach}

We may identify three features of capability approach - (1) Going beyond achievement to opportunity, (2) Fear of non-commensurability (measurability) and (3) Valuation and Public Reasoning. These are further elaborated as follows:

\subsection{Going beyond achievement to opportunity}

Capability is defined on functioning and includes all the information on the functioning combinations that a person can choose. If choice is based on achieved functioning then freedom to choose is lost. Freedom has only instrumental value. Example: Imagine a well off person choosing to fast for political or religious purpose, amidst alternative not to fast and a poor person having to fast due to hunger. In both the cases, achieved functioning is same, yet in former case freedom to choose different kinds of lives within their reach bestows high capability.

\subsection{Fear of non-commensurability (measurability)}

Capabilities are non commensurable since they are irreducibly diverse unlike utility and GNP. Non commensurability is present when several dimensions of value are irreducible to one another. However, in real world in making real choices between alternatives which are non-commensurable such as going for holiday trip or medical attention, we do make reasoned choice.

\subsection{Valuation and Public Reasoning}

Public reason is the basis for evaluating relative priorities, not just counting (in terms of utility number). Social evaluation, particular, in policy areas may be starved of useful information and good arguments if public deliberation not permitted. Public reasoning has been useful in questioning 'fixed time hour' of work for women. This allows new and interesting questions to emerge. No ground for predetermined weights. Lack of predetermined weights may not disrupt evaluation of injustices. The main task is to get things right on comparative evaluation.

\section{Capabilities, Individuals and Communities}

It would be a mistake to identify capability approach with methodological individualism. It is possible to talk about communities' capabilities such as tribal communities, Muslim communities' capabilities. In fact, individual is not detached from society. Capability perspective demands more public engagement on many issues which lead to suffering of individual but is grounded in social conditioning. The concept of impartial spectator established relevance of society in the valuation. This social evaluation is consistent with the idea that it is individuals who think, choose and do. An important point is that a person has multiple identities by being member of different social groups, and not the one. Hence an individual choice and action can only be understood in terms plural identities and multiple affiliations, certainly not in terms of methodological individualism.

\section{Sustainable development, environment and global justice}

Sen has illustrated with examples importance of environmental sustainability for preserving and enhancing the quality of life thereby enlarging capabilities of human being. At the same time this process of empowerment through education etc. can construct environment which is friendly to the people. Example of environmental sustainability is then proposed to argue in favour of expansion and sustainability of freedom. Also central to the argument in favour of capability is the importance of human lives.

Finally, Sen has by talked about a synoptic view of the global justice. Here again, he establishes the redundancy of the transcendental institutional approach as a matter of utopia, without having applicability inabsence of a global institutional governance/framework. The demand for global justice and institutional reforms, according to Sen, is essentially targeted towards elimination of cases of manifest injustice (such as, apartheid, slavery) rather than towards a perfectly just world society. 


\section{Conclusion}

In the context of policy implications based on contents of Sen's analysis of social justice, a few underlying objective principles can be derived. First and foremost, policy at the conceptual stage should be based on understanding of issues (problems) at the ground level (social and actual realisations). Subsequently, it entails a reasoned analysis based on public reasoning and identification and ranking of feasible alternatives that can be realised in practice. Merely taking a transcendental view in policy making to achieve an idyllic premonition of social justice would be rather futile in realisation of desired objectives.For example, the target of 'Universalisation of Elementary Education' by adopting a policy of Sarva Siksha Aviyan by the Government of India has largely failed to meet its goal due to non-perceiving of ground realities like demand for education, availability and nationwide distribution of teachers across schools, regional and social disparities etc.

Secondly, policy perspectives should be understood also as a matter of process (comprehensive outcome) rather than only as a culmination outcome. The means of reaching a socially desirable objective through policy has far greater implications than focussing on the end result itself. For example, we talk about massification of higher education in India in terms of surge in GER (the end result). But if we carefully analyse the process behind such progressing GER, we will find that it is happening mostly due to a sudden spurt of private HEIs in India without having much consideration about quality, access and equity issues which are far greater and crucial socially desirable parameters.

Thirdly, Sen has eloquently developed throughout his whole theory a capability-based approach in terms of empowerment of individuals by means of giving them freedom to choose about their lives in order to move towards a more 'just' egalitarian society. Social realisations in terms of capabilities, as opposed to utilities or happiness, would make individuals more enable as well as accountable. This is a very fundamental departure from the traditional utilitarian philosophy behind any public policy formulation strategy. A welfare state, by its policy doctrines, should endeavour to provide more freedom 'to reason and choose' to its citizens rather than only attempting just institutional arrangements in order to create a flourishing human society, in general.

\section{References}

Kukathas, C. (2013), "Sen on Comparative Justice", Critical review of international social and political philosophy, Vol 16, Issue - 2

Murphy, T. (2010), "A Review of Sen: Idea of Justice", Researchgate.net

Newberg, P. (2009/2018), "Review: The Idea of Justice", The Globe and Mail Inc.

Sen, A. (2009), "The Idea of Justice", Penguin 